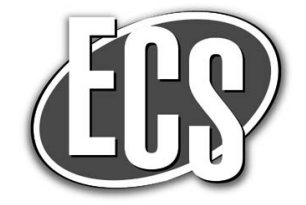

JSS Focus Issue on Printable Functional Materials for Electronics and Energy Applications

\title{
A Tetrabenzotriazaporphyrin Based Organic Thin Film Transistor: Comparison with a Device of the Phthalocyanine Analogue
}

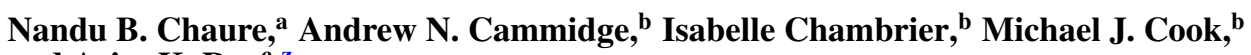 \\ and Asim K. Ray ${ }^{,, z}$ \\ ${ }^{a}$ Department of Physics, University of Pune, Ganeshkhind, Pune 411007, India \\ ${ }^{b}$ School of Chemistry, University of East Anglia, Norwich NR4 7TJ, United Kingdom \\ ${ }^{c}$ Institute of Materials and Manufacturing, Brunel University London, Uxbridge, Middlesex UB8 3PH, United Kingdom
}

\begin{abstract}
The characteristics of bottom-gate bottom-contact organic thin film field-effect transistors (OTFTs) with $70 \mathrm{~nm}$ thick films of solution processed non-peripherally octahexyl-substituted nickel tetrabenzo triazaporphyrin (6NiTBTAP) molecules as active layers on silicon substrates are experimentally studied and the results are compared with the similary configured transistors using the corresponding nickel phthalocyanine $(6 \mathrm{NiPc}$ ) compound. 6NiTBTAP transistors are found to exhibit improved performance over $6 \mathrm{NiPc}$ transistors in terms of greater saturation hole mobility, two orders of magnitude higher on/off ratio and lower threshold voltage. This enhanced performance of 6NiTBTAP OTFTs over 6NiPc devices is attributed to improved surface morphology and large grain size of the active 6NiTBTAP film.

(C) The Author(s) 2015. Published by ECS. This is an open access article distributed under the terms of the Creative Commons Attribution Non-Commercial No Derivatives 4.0 License (CC BY-NC-ND, http://creativecommons.org/licenses/by-nc-nd/4.0/), which permits non-commercial reuse, distribution, and reproduction in any medium, provided the original work is not changed in any way and is properly cited. For permission for commercial reuse, please email: oa@ electrochem.org. [DOI: 10.1149/2.0131504jss] All rights reserved.
\end{abstract}

Manuscript submitted December 8, 2014; revised manuscript received February 14, 2015. Published February 26, 2015. This paper is part of the JSS Focus Issue on Printable Functional Materials for Electronics and Energy Applications.

Recent years have seen immense research activities in the development of high performance organic thin film field-effect transistors (OTFTs) with emphasis on low cost deposition of materials with novel characteristics over large areas on both solid and flexible substrates for multiple applications including displays, large-volume microelectronics, and biological and environmental sensors. ${ }^{1-3}$ High on-off ratio in the order of $10^{7}$, threshold voltage as low as $1 \mathrm{~V}$ and field effect hole mobility of approximately $1.21 \mathrm{~cm}^{2} \mathrm{~V}^{-1} \mathrm{~s}^{-1}$ are reported for OTFTs using thin films of small molecules such as pentacene, ${ }^{4}$ porphyrazine, ${ }^{5}$ rubrene, ${ }^{6}$ and thiophene ${ }^{7,8}$ derivatives with suitably selected gate dielectrics. Among these small molecules, phthalocyanines (Pc) which constitute a class of macrocyclic compounds with a remarkable range of optical, optoelectronic and electrical properties are well-recognized for their chemical and thermal stability and UV-resistance. Their potential as organic semiconductors has been extensively pursued for the employment of vacuum deposited active layers in OTFTs. ${ }^{9}$ Of particular interest, however, are those low molecular weight Pc derivatives that bear substituent groups that confer solubility in common organic spreading solvents and columnar liquid crystal behavior typically at elevated temperatures. ${ }^{10,11}$ Time of flight measurements have reported remarkably high hole mobilities of $1.4 \mathrm{~cm}^{2} \mathrm{~V}^{-1} \mathrm{~s}^{-1}$ for substituted metal free phthalocyanine compounds, when in their liquid crystal phases. ${ }^{12-14}$ Transistor experiments on films of a copper metallated derivative bearing eight hexyl chains at non-peripheral sites, $6 \mathrm{CuPc}$ Figure 1, demonstrated the importance of the annealing temperature in optimising the electrical behavior, leading in particular to field effect hole mobilities of the order of $0.7 \mathrm{~cm}^{2} \mathrm{~V}^{-1} \mathrm{~s}^{-1}$ for the films annealed at $100^{\circ} \mathrm{C} .{ }^{15}$ The solution processing for formulation of molecules into thin films is suitable for roll-to-roll deposition onto large area substrates both solid and flexible. ${ }^{16}$

In this paper, bottom-gate, bottom-contact organic thin film field effect transistors have been prepared on the highly doped silicon (110) gate electrode substrates using solution processed thin films of nickel$1,4,8,11,15,18,22,25$-octakis(hexyl)phthalocyanine (6NiPc) and correspondingly substituted tetrabenzotriazaporphyrin (6NiTBTAP) in Figure 1. TBTAPs are closely related to Pcs and differ only in the number of nitrogen atoms in the central core of the molecule. Unlike Pcs, TBTAPs have received very limited investigation, not least because of

${ }^{\text {z} E-m a i l: ~ a s i m . r a y @ b r u n e l . a c . u k ~}$ the need for more complex synthetic chemistry to provide the lower symmetry ring system. ${ }^{17,18}$ Due to the replacement of one of the nitrogen atoms by a methine unit at a mesobridging position of the Pc ring, the appearance of strong B and Q bands was observed at $350 \mathrm{~nm}$ and $700 \mathrm{~nm}$ respectively in UV and visible region optical absorption spectra of thin films of similarly substituted metal-free liquid crystalline TBTAP molecules and this special characteristic has been found to be suitable for employing this ambipolar molecule in the high efficiency bulk heterojunction organic solar cells having fill factor of $0.65{ }^{19}$ This article presents the results of an investigation into relative performances of these two devices in terms of the film conductivity $(\sigma)$, saturation mobility $\left(\mu_{\mathrm{sat}}\right)$, sub-threshold voltage swing $(S)$, threshold voltage $\left(\mathrm{V}_{\mathrm{T}}\right)$ and on-off ratio. These parameters are dependent upon the morphology and grain size of the active organic films and therefore, the atomic force microscopic studies on the topography of both films have been studied. The results indicate the improved properties of OTFTs of 6NiTBTAP over those for $6 \mathrm{NiPc}$.

\section{Experimental}

The preparation of $6 \mathrm{NiPc}$ was straightforward, using the wellestablished sequence of macrocyclization of 3,6-dihexylphthalonitrile (using lithium pentoxide in pentanol) followed by insertion of nickel. The synthesis of 6NiTBTAP compound was recently developed and is achieved by initiation of the macrocyclization with methylmagnesium iodide followed by heating in quinoline. Nickel was again inserted in the second step using nickel acetate as shown in Figure 1. The synthesis of 6NiTBTAP compound was first described in an earlier publication. ${ }^{20}$ Bottom-gate, bottom-contact organic thin film transistors (OTFTs) were fabricated on octadecyltrichlorosilane (OTS) treated $250 \mathrm{~nm}$ thick $\mathrm{SiO}_{2}$ gate insulator on the highly doped (resistivity 1 to $5 \Omega \mathrm{cm}$ ) Si (110) substrate in the following stages. Plasma enhanced chemical vapor deposition method was employed to deposit this gate dielectric $\mathrm{SiO}_{2}$ layer. Prior to the device fabrication, the substrates were cleaned thoroughly in acetone, iso-propanol and finally in deionized water. For passivation of dangling bonds and interfacial traps, deposition of an OTS self-assembled monolayer onto the substrate was undertaken using OTS dissolved in anhydrous toluene above $50^{\circ} \mathrm{C} .{ }^{21}$ Spin-coated films of the two macrocyclic compounds, i.e $6 \mathrm{NiTBTAP}$ and $6 \mathrm{NiPc}$ were used as the active semiconductor layer on source-drain electrodes of photolithographically pre-patterned 


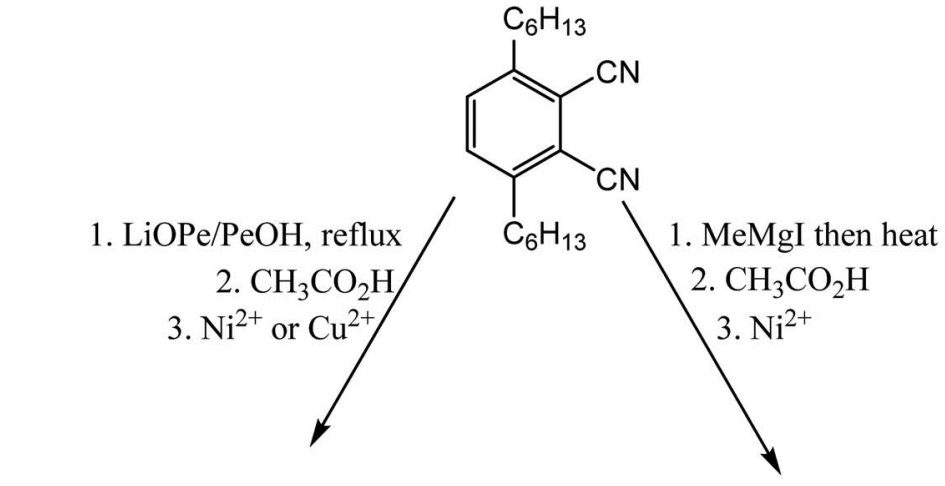

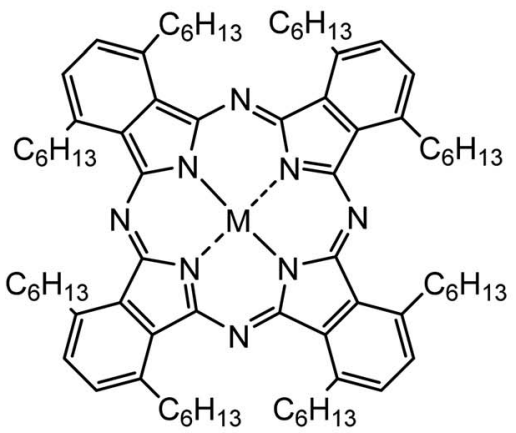

$6 \mathrm{CuPc}(\mathrm{M}=\mathrm{Cu})$ $6 \mathrm{NiPc}(\mathrm{M}=\mathrm{Ni})$

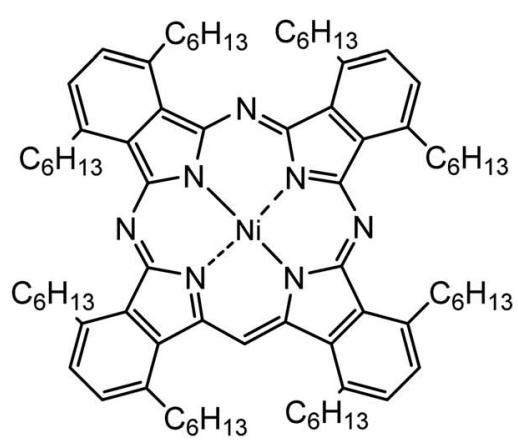

Figure 1. Synthesis and chemical structures of nickel tetrabenzotriazaporphyrin (6NiTBTAP), nickel and copper phthalocyanine $(6 \mathrm{NiPc}$ and $6 \mathrm{CuPc})$, each bearing eight hexyl chains (C6H13) on non-peripheral sites.
$200 \mathrm{~nm}$ thick titanium/gold in an interdigitated configuration with channel length $\mathrm{L}=5 \mu \mathrm{m}$ and channel width $\mathrm{W}=2 \mathrm{~mm}$. For spin coating, the compounds were dissolved in high purity chloroform $(5 \mathrm{mg} / 1 \mathrm{~mL})$ to prepare a spreading solution and a small volume of the resulting solution was then spin-coated initially at $1000 \mathrm{rpm}$ for 20 secs and finally at $4000 \mathrm{rpm}$ for 60 secs. The thickness of the sample was found to be $70 \mathrm{~nm}$ from the stylus profilometric measurements. The Si substrate with Au contacts on the reverse side acted as the gate electrode and an approximately $10 \mathrm{~nm}$ seed layer of chromium was used for good adhesion. The full protocols of the substrate cleaning, electrode deposition and surface passivation were given in a previous publication. ${ }^{21}$ The electrical measurements were performed at room temperature in air under ambient conditions using a Keithley 4200 semiconductor parameter analyzer. The topographical images of the films spin coated on the $20 \mathrm{~mm} \times 20 \mathrm{~mm}$ silicon substrate were examined by the Digital Nanoscope III, Atomic Force Microscope (AFM) in non-conducting mode.

\section{Results and Discussion}

Figure $2 \mathrm{a}$ and $2 \mathrm{~b}$ shows the 2-dimensional AFM micrographs of asprepared $6 \mathrm{NiTBTAP}$ and $6 \mathrm{NiPc}$, respectively. A Long grain fibre-like morphology of size $\sim 1 \mu \mathrm{m}$ to $2 \mu \mathrm{m}$ can be clearly seen in as-prepared 6NiTBTAP sample, whereas randomly oriented short nanorods $\sim 200 \mathrm{~nm}$ to $300 \mathrm{~nm}$ were observed in $6 \mathrm{NiPc}$ devices. Both films were very compact and well adherent and uniformly deposited all over the $20 \mathrm{~mm} \times 20 \mathrm{~mm}$ area of substrate. Root mean square values of $24 \mathrm{~nm}$ and $32 \mathrm{~nm}$ were estimated for surface roughness of 6NiTBTAP and $6 \mathrm{NiPc}$ films, respectively.

Figure 3 shows a set of typically reproducible output characteristics in terms of drain-source current $\left(\mathrm{I}_{\mathrm{D}}\right)$ as a function of drain-source voltage $\left(\mathrm{V}_{\mathrm{D}}\right)$ with varying the negative gate voltage $\left(\mathrm{V}_{\mathrm{G}}\right)$ from $0 \mathrm{~V}$ to $50 \mathrm{~V}$. The increase of drain-source conductivity with $\mathrm{V}_{\mathrm{G}}$ indicates OTFTs exhibit a clean field-effect with operation in a p-type accu- mulation mode. At the negative gate bias, the voltage drop over the interface between the gate dielectric and the active semiconductor layer causes the band bending in the active organic layers and as a result an accumulation layer is formed from the additional supply of positive charges from the drain and source contacts. The organic molecules are inherently p-type and, therefore, the active layers also receive additional positive charges due to the formation of accumulation layer arising from the field effect.

Although the currents are of the same order of magnitude for both devices, $I_{D}$ in the triode region is found to increase more slowly for the $6 \mathrm{NiPc}$ OTFT than 6NiTBTAP. This implies that the $6 \mathrm{NiPc}$ active layer forms the Schottky barriers at the source contact, restricting the tunnelling type current flow. ${ }^{22}$ The change of the drain-source current with the drain voltage is significantly small for zero gate voltage, implying that the OTFTs are normally off. The measurements of $I_{D}$ at low $V_{D}$ are important for determining an essential material parameter such as Ohmic film conductivity and values are estimated to be $14.3 \mu \mathrm{S}^{-1}$ and $1.8 \mu \mathrm{S}^{-1}$ for $6 \mathrm{NiTBTAP}$ and $6 \mathrm{NiPc}$, respectively from the formula in the form: ${ }^{23}$

$$
\sigma=\left.\left(\frac{L}{W t}\right) \frac{I_{D}}{V_{D}}\right|_{V_{G} \rightarrow 0, V_{D} \rightarrow 0}
$$

The nearly eight fold increase in the 6NiTBTAP film conductivity may be attributed to easy charge transfer along long grain fibre like morphology.

The transfer characteristic in Figure 4 of drain-source current versus gate voltage for drain-source voltage $V_{D}=-40 \mathrm{~V}$ exhibits on/off current ratio of $10^{5}$ and $10^{3}$ for 6NiTBTAP and 6NiPc OTFTs, respectively. The positive charges in the 6NiTBTAP device become completely depleted over the entire thickness of the active layers at the gate voltage of $\mathrm{V}_{\mathrm{G}}=5 \mathrm{~V}$, which is lower than $\mathrm{V}_{\mathrm{G}}=10 \mathrm{~V}$ for 6 NiPc OTFTs. This depletion is caused by the band bending of the active organic layers in the opposite direction at the gate interface. 

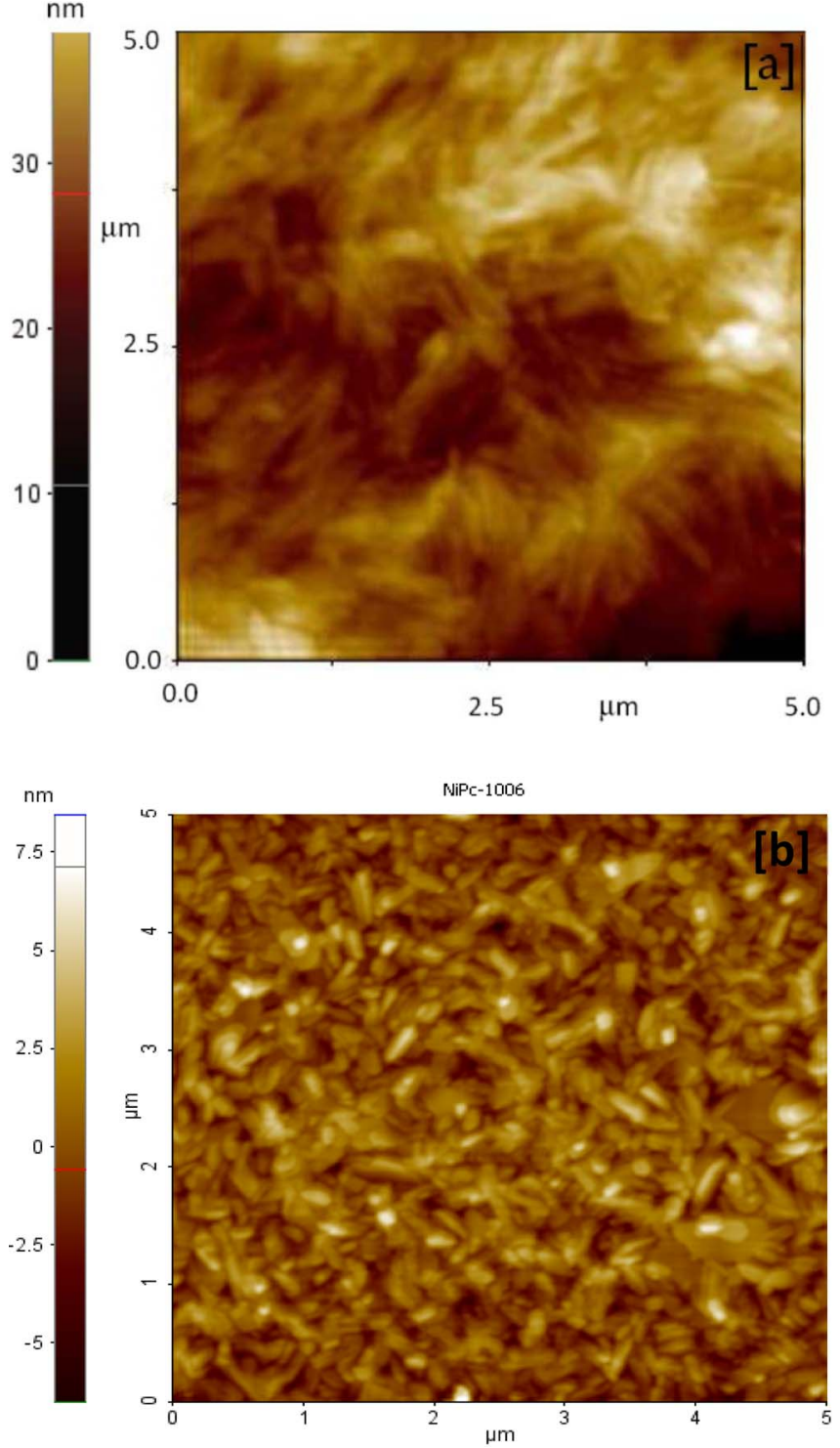

Figure 2. 2-dimensional AFM micrographs of (a) 6NiTBTAP and (b) $6 \mathrm{NiPc}$ OFET's devices.

The sub-threshold voltage swing $S$ which is defined as the voltage $V_{G}$ required to increase $I_{D}$ by a factor of 10 was estimated to be 1.4 decade $^{-1}$ and 2.8 decade $^{-1}$ for 6NiTBTAP and 6NiPc OTFTs, respectively using the formula in the form:

$$
\mathrm{S}=\frac{\mathrm{dV}_{\mathrm{G}}}{\mathrm{d}\left(\log \mathrm{I}_{\mathrm{D}}\right)}
$$

The density $\mathrm{N}_{\mathrm{ss}}$ of traps at the interface between the organic layer and the gate $\mathrm{SiO}_{2}$ dielectrics is related to the sub-threshold voltage swing $\mathrm{S}$ in the form: ${ }^{23}$

$$
\mathrm{N}_{\mathrm{ss}}=\left[\frac{\mathrm{S} \log (\mathrm{e})}{\mathrm{kT}}-1\right] \frac{\mathrm{C}_{\mathrm{i}}}{q}
$$

Values of $\mathrm{N}_{\mathrm{ss}}$ are estimated to be $3.89 \times 10^{12} \mathrm{eV}^{-1} \mathrm{~cm}^{-2}$ and $7.43 \times 10^{12} \mathrm{eV}^{-1} \mathrm{~cm}^{-2}$ for 6NiTBTAP and 6NiPc OTFTs, respectively. $C_{i}$ is the capacitance/unit area for the OTS treated gate layer is estimated to be $1 \times 10^{-4} \mathrm{Fm}^{-2}$ using the value of $1 \times 10^{-4} \mathrm{Fm}^{-2}$ for the capacitance of an OTS monolayer, $q$ is the electronic charge.

The behavior of the drain current $\left(\mathrm{I}_{\mathrm{D}}\right)$ of transistors in saturation regime is commonly described in the following standard quadratic
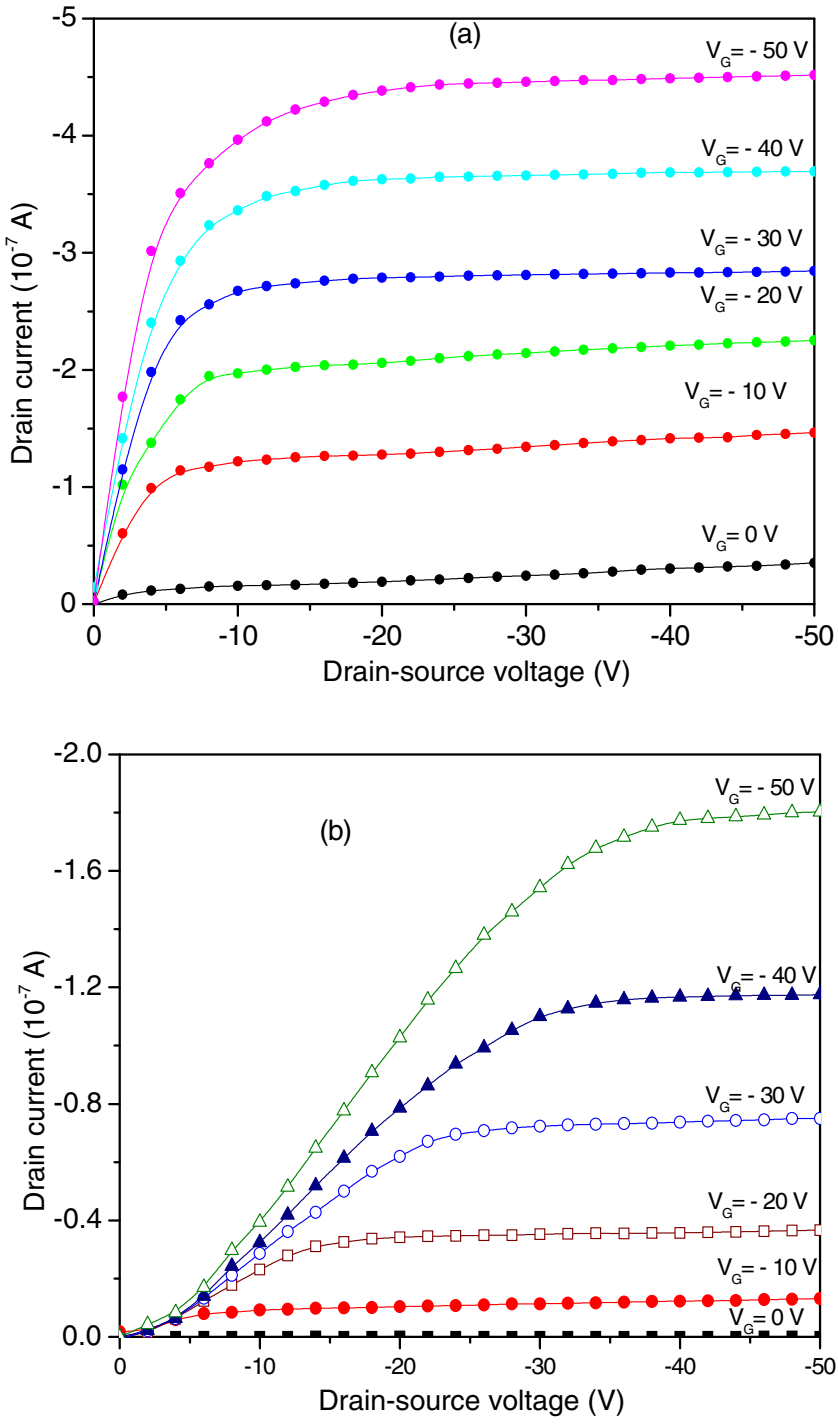

Figure 3. Output characteristics for OTFTs with (a) 6NiTBTAP and (b) $6 \mathrm{NiPc}$.

equation form:

$$
I_{D}=\mu_{s a t} \frac{W}{2 L} \mathrm{C}_{\mathrm{i}}\left(V_{G}-V_{T}\right)^{2}
$$

$\mathrm{V}_{\mathrm{T}}$ is the threshold voltage at which the conduction channel begins to form and $\mu_{\text {sat }}$ is the saturation mobility.

Values of $\mu_{\text {sat }}$ are found to be $9.0 \times 10^{-3} \mathrm{~cm}^{2} \mathrm{~V}^{-1} \mathrm{~s}^{-1}$ and 7.0 $\times 10^{-3} \mathrm{~cm}^{2} \mathrm{~V}^{-1} \mathrm{~s}^{-1}$ for 6NiTBTAP and 6NiPc OTFTs, respectively from the slopes of the best linear fits in Figure 4 to the square-root dependence of $I_{D}$ on $V_{G}$. However, it is to be noted that the dependence of $I_{D}$ on the gate $V_{G}$ is not strictly linear and the variation of the field effect mobility with gate voltage should be taken into account for detailed analysis. ${ }^{24}$ The on/off ratio $\frac{\mathrm{I}_{\mathrm{on}}}{\mathrm{I}_{\mathrm{off}}}$ may be written in the form: ${ }^{23}$

$$
\frac{\mathrm{I}_{\mathrm{on}}}{\mathrm{I}_{\mathrm{off}}}=\left(\frac{\mu_{\mathrm{sat}}}{\mathrm{q} \sigma \mathrm{N}_{\mathrm{A}}}\right)\left(\frac{\mathrm{C}_{\mathrm{i}} \mathrm{V}_{\mathrm{D}}}{\mathrm{t}}\right)^{2}
$$

The ratio of the doping concentration $\mathrm{N}_{\mathrm{A}}$ for the 6NiTBTAP layer to that of $6 \mathrm{NiPc}$ layer is found to be $6.2 \times 10^{-2}$. This indicates that the 6NiTBTAP film is lightly doped. The field effect is more pronounced in the $6 \mathrm{NiTBTAP}$ than in the $6 \mathrm{NiPc}$ layer, producing two orders of magnitude higher on/off ratio due to very low off current caused by depletion of accumulated charges. 

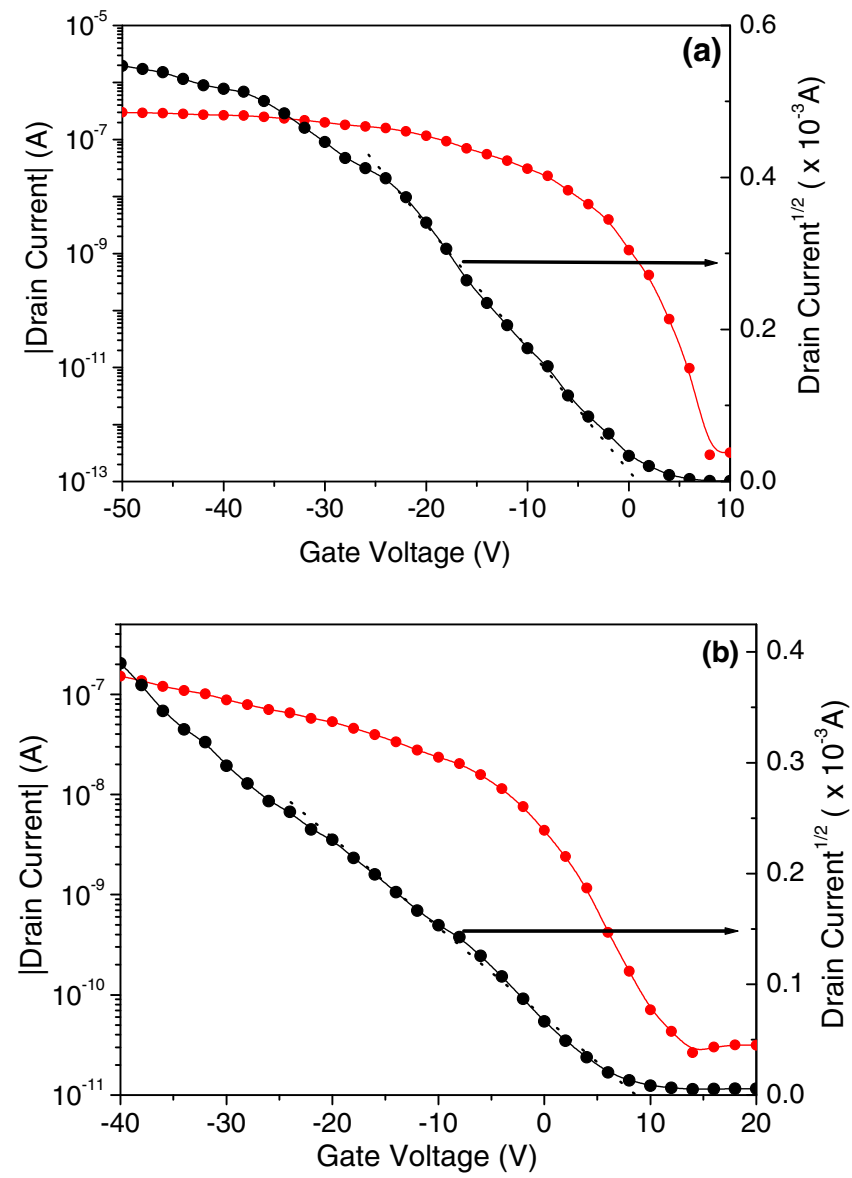

Figure 4. Transfer characteristics and plots of square root of $I_{D}$ vs $V_{G}$ for OTFTs with (a) 6NiTBTAP and (b) $6 \mathrm{NiPc}$ for $\mathrm{V}_{\mathrm{D}}=-45 \mathrm{~V}$.

Values of $5 \mathrm{~V}$ and $8 \mathrm{~V}$ are obtained for threshold voltage $\mathrm{V}_{\mathrm{T}}$ of $6 \mathrm{NiTBTAP}$ and $6 \mathrm{NiPc}$ transistors from the intercepts on the abscissa axis. $\mathrm{V}_{\mathrm{T}}$ is believed to be related to the bulk trap limited charge transport in the organic layer and the density $\mathrm{N}_{\mathrm{B}}$ of these traps is related to $\mathrm{V}_{\mathrm{T}}$ in the form: ${ }^{25}$

$$
\mathrm{N}_{\mathrm{B}}=\frac{\mathrm{V}_{\mathrm{T}}^{2} \mathrm{C}_{\mathrm{i}}^{2}}{2 \varepsilon_{\mathrm{pc}} \varepsilon_{0} \mathrm{kT}}
$$

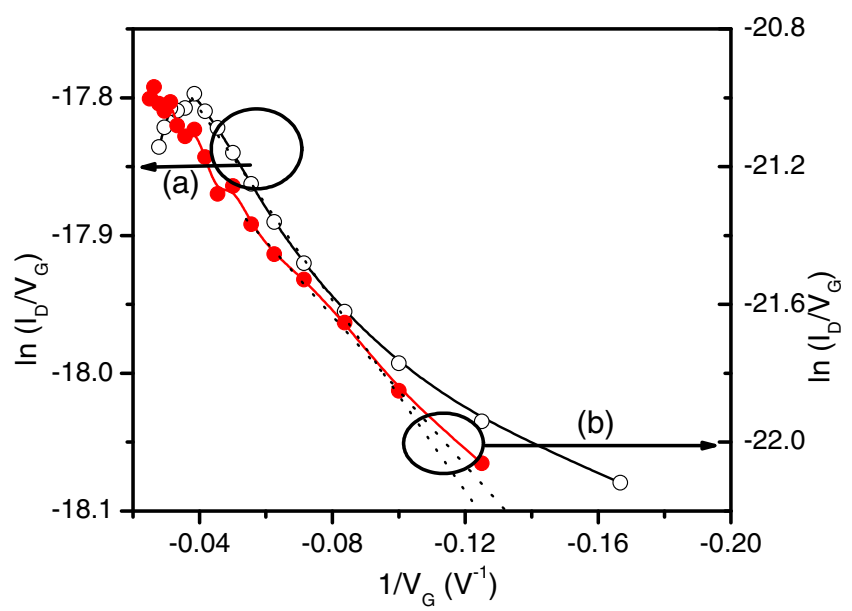

Figure 5. Levinson plot of OTFTs with (a) 6NiTBTAP (open circles) and (b) $6 \mathrm{NiPc}$ (stars) as variation of $\ln \left(I_{D} / V_{G}\right)$ as function of $\frac{1}{V_{\mathrm{G}}}$ for $\mathrm{V}_{\mathrm{D}}=-5 \mathrm{~V}$.

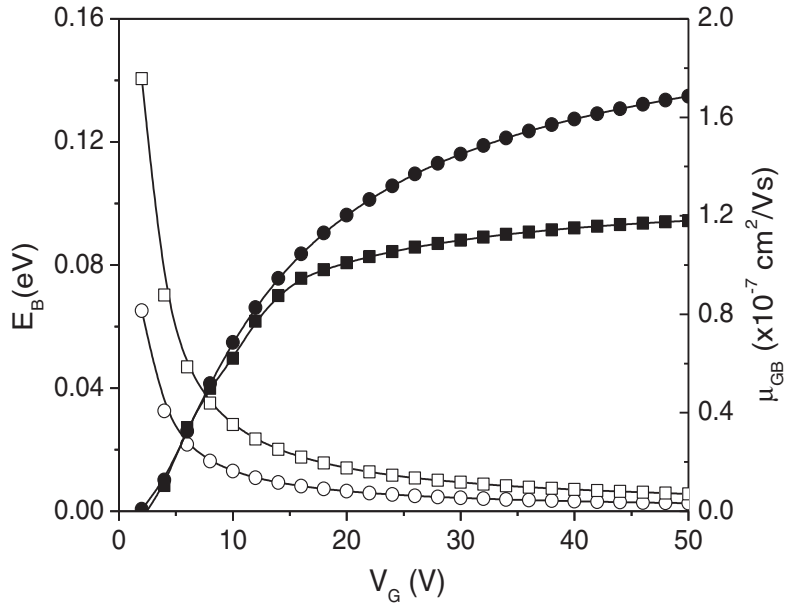

Figure 6. Dependence of grain boundary barrier $E_{\mathrm{B}}$ (open symbols) and the grain boundary mobility $\mu_{\mathrm{GB}}$ (closed symbols) on the gate voltage (a) 6NiTBTAP (circles) and (b) $6 \mathrm{NiPc}$ (rectangles).

Values of $\mathrm{N}_{\mathrm{B}}=2.3 \times 10^{17} \mathrm{~cm}^{-3}$ and $\mathrm{N}_{\mathrm{B}}=5.9 \times 10^{17} \mathrm{~cm}^{-3}$ are found for $6 \mathrm{NiTBTAP}$ and $6 \mathrm{NiPc}$ films. The free permittivity $\varepsilon_{0}$ $=8.85 \times 10^{-12} \mathrm{Fm}^{-1}$ and the value for the dielectric constant of the active organic films $\varepsilon_{\mathrm{pc}}=3$ were used for the calculation. The ratio of surface roughness of $6 \mathrm{NiTBTAP}$ to that of $6 \mathrm{NiPc}$ films is 0.75 where a similar ratio of the values of $\mathrm{N}_{\mathrm{B}}$ is found to be 0.38 . Although there is no strict correlation between these two ratios, the decrease of bulk trap density is consistent with low surface roughness obtained from earlier AFM studies.

The quantitative examination of the dependence of the OTFT characteristics on the grain boundaries in the active layers was made from the Levinson plots in Figure 5 of $\ln \left(\frac{I_{\mathrm{D}}}{V_{G}}\right)$ vs. $\frac{1}{V_{G}}$ for $V_{D}=-5 \mathrm{~V}$. The linear graphs show the dependence of $\mathrm{I}_{\mathrm{DS}}$ on the density $\mathrm{N}_{\mathrm{g}}$ of traps at the grain boundaries of the phthalocyanine layer in the form: ${ }^{26}$

$$
\mathrm{I}_{\mathrm{D}}=\mu_{\mathrm{GB} 0} \mathrm{~V}_{\mathrm{D}} \frac{\mathrm{W}}{\mathrm{L}} \mathrm{C}_{\mathrm{i}} \mathrm{V}_{\mathrm{G}} \exp \left(-\frac{\mathrm{q}^{3} \mathrm{~N}_{\mathrm{g}}{ }^{2} \mathrm{t}}{8 \varepsilon_{0} \varepsilon_{\mathrm{pc}} \mathrm{kTC}_{\mathrm{i}} \mathrm{V}_{\mathrm{G}}}\right)
$$

where $\mu_{\mathrm{GB} 0}$ usually depends on the grain size and the carrier concentration, but only slightly on measurement temperature.

Values of $8.98 \times 10^{11} \mathrm{~cm}^{-2}$ and $3.65 \times 10^{12} \mathrm{~cm}^{-2}$ for the grain boundary density $\mathrm{N}_{\mathrm{g}}$ were determined for $6 \mathrm{NiTBTAP}$ and $6 \mathrm{NiPc}$ films, respectively from the slope of the Levinson plots. Free trap mobilities $\mu_{\mathrm{GBO}}$ are $2.11 \times 10^{-7} \mathrm{~cm}^{2} \mathrm{~V}^{-1} \mathrm{~s}^{-1}$ and $1.31 \times 10^{-7} \mathrm{~cm}^{2} \mathrm{~V}^{-1} \mathrm{~s}^{-1}$ for 6NiTBTAP and 6NiPc layers, respectively. Figure 6 shows that the grain boundary barrier $\mathrm{E}_{\mathrm{B}}$ decreases while the grain boundary mobility $\mu_{\mathrm{GB}}$ increase with $\mathrm{V}_{\mathrm{G}}$. Values of $\mathrm{E}_{\mathrm{B}}$ for both types of the devices are found to undergo sharp decreases at low voltage $V_{G} \leq V_{T}$ and then the reduction tends to be steady. Values of smaller $\mathrm{E}_{\mathrm{B}}$ and higher $\mu_{\mathrm{GB}}$ for $6 \mathrm{NiTBTAP}$ than $6 \mathrm{NiPc}$ OTFTs are also in agreement with the earlier observation of AFM based morphology studies.

\section{Conclusions}

Approximately $70 \mathrm{~nm}$ thick spin-coated films of non-peripherally substituted nickel tetrabenzotriazaporphyrin molecules and their phthalocyanine analogues are employed as active semiconducting

\begin{tabular}{|c|c|c|c|c|}
\hline Compound & $\begin{array}{l}\text { Saturation } \\
\text { Mobility } \\
\left(\mathrm{cm}^{2} / \mathrm{Vs}\right)\end{array}$ & $\begin{array}{c}\text { On/off } \\
\text { current } \\
\text { ratio }\end{array}$ & $\begin{array}{c}\text { Threshold } \\
\text { voltage }\left(\mathrm{V}_{\mathrm{T}}\right) \\
(\mathrm{V})\end{array}$ & $\begin{array}{c}\text { Saturated } \\
\text { source-drain } \\
\text { current (A) }\end{array}$ \\
\hline & $9.0 \times 10^{-3}$ & $>10^{5}$ & 5 & $4.5 \times 10^{-7}$ \\
\hline $6 \mathrm{NiPc}$ & $7.0 \times 10^{-3}$ & $\sim 10^{3}$ & 8 & $1.8 \times 10^{-7}$ \\
\hline
\end{tabular}

Table I. Organic thin film transistor device characteristics. 
layers in the fabrication of field effect transistors in bottom gate configurations. Comparative performances of these two devices are experimentally studied and the results of the measurements are summarized in Table I. The 6NiTBTAP transistor exhibits superior performance in terms of (i) high mobility, (ii) low threshold voltage, (iii) large on/off current ratio, and (iv) steeper sub-threshold slope. Both compounds can be utilized in printable electronics for large area roll-to-roll deposition on flexible substrates. Compactly packed long fibres observed in the 6NiTBTAP film are believed to be responsible for enhanced in-plane charge transport in the channel between the drain and the source. The grain boundaries in randomly oriented nano-rods in the $6 \mathrm{NiPc}$ films with a relatively rougher surface, on the other hand, act as traps for charge carriers.

\section{Acknowledgments}

Experimental work was carried out at Queen Mary, University of London under financial support from the UK Technology Strategy Board (Project No: TP/6/EPH/6/S/K2536J). The pre-patterned transistor substrates were prepared by QUDOS Technology, Rutherford Appleton Laboratory, Didcot, UK. The authors are grateful to Dr Craig E. Murphy and Dr Markys G. Cain of the National Physical Laboratory, Hampton Road, Teddington, Middlesex UK for fruitful discussions.

\section{References}

1. B. Kumar, B. K. Kaushik, and Y. S. Negi, Polymer Reviews, 54, 33 (2014).

2. E. G. Wang, W. Mammo, and M. R. Andersson, Adv. Mater., 26, 1801 (2014).

3. Q. Meng, H. L. Dong, W. P. Hu, and D. B. Zhu, J. Mater. Chem., 21, 11708 (2011).

4. C. Y. Han, W. M. Tang, C. H. Leung, C. M. Che, and P. T. Lai, Org. Electron., 15, 2499 (2014).

5. M. Shahid, N. Padamsey, J. Labram, T. D. Anthopoulos, and M. Heeney, J. Mater. Chem. C., 1, 6198 (2013).
6. S. Ono, R. Haeusermann, D. Chiba, K. Shimamura, T. Ono, and B. Batlogg, Appl. Phys. Lett., 104, Article Number: 013307 (2014).

7. D. C. Borrelli, S. Lee, and K. K. Gleason, J. Mater. Chem. C, 2, 7223 (2014).

8. B. Zhou, P. C. Huang, and C. L. Liu, J. Mater. Sci.-Mater. Electron., 5, 3727 (2014).

9. S. Sinha, C. H. Wang, M. Mukherjee, and Y. W. Yang, J. Phys. D-Appl. Phys., 47, Article Number: 245103 (2014).

10. M. J. Heeney, S. A. Al-Raqa, A. Auger, P. M. Burnham, A. N. Cammidge, I. Chambrier, and M. J. Cook, J. Porphyr. Phthalocyanines., 17, 649 (2011).

11. H. Iino, J-I. Hanna, R. J. Bushby, B. Movaghar, B. J. Whitaker, and M. J. Cook, Appl. Phys. Lett., 87, 132102 (2005)

12. Y. Miyake, Y. Shiraiwa, K. Okada, H. Monobe, T. Hori, N. Yamasaki, H. Yoshida, M. J. Cook, A. Fugii, M. Ozaki, and Y. Shimizu, Appl. Phys. Express, 4, 021604 (2011).

13. Y. Shimizu, Y. Miyake, H. Yoshida, H. Monobe, M. J. Cook, A. Fugii, and M. Ozaki, Mol. Cryst. Liq. Cryst., 549, 127 (2011).

14. H. Iino, J-I. Hanna, R. J. Bushby, B. Movaghar, B. J. Whitaker, and M. J. Cook Appl. Phys. Lett., 87, 132102 (2005).

15. N. B. Chaure, C. Pal, S. Barard, T. Kreouzis, A. K. Ray, A. N. Cammidge, I. Chambrier, M. J. Cook, C. E. Murphy, and M. G. Cain, J. Mater. Chem., 22, 19179 (2012).

16. R. R. Sondergaard, M. Hosel, and F. C. Krebs, J. Polym. Sci. Pt. B-Polym. Phys., 51, $16(2014)$.

17. A. N. Cammidge, I. Chambrier, M. J. Cook, and L. Sosa-Vargas, Synthesis and Properties of the Hybrid Phthalocyanine-Tetrabenzoporphyrin Macrocycles in Handbook of Porphyrin Science, Vol. 16, K. M. Kadish, K. M. Smith, and R. Guilard (Eds), World Scientific Publishing Company, Singapore, pp. 331 (2012).

18. A. Diaz-Moscoso, G. J. Tizzard, S. J. Coles, and A. N. Cammidge, Angew. Chem. Int. Ed., 52, 10784 (2013).

19. Q. D. Dao, K. Watanabe, H. Itani, L. Sosa-Vargas, A. Fujii, Y. Shimizu, and M. Ozaki, Chem. Lett., 43(11), 1761 (2014).

20. A. N. Cammidge, I. Chambrier, M. J. Cook, D. L. Hughes, and M Rahmanand L. Sosa-Vargas, Chem.-Eur. J., 17, 3136 (2011).

21. N. B. Chaure, A. N. Cammidge, I. Chambrier, M. J. Cook, M. G. Cain, C. E. Murphy, C. Pal, and A. K. Ray, Sci. Technol. Adv. Mater., 12, 025001 (2011).

22. G. Yip, S. Sugimoto, and R. Hattori, Korean Phys. Soc. 48,102 (2006).

23. A. R. Brown, C. P. Jarrett, D. M. de Leeuw, and M. Matters, Synth. Met., 88, 37 (1997).

24. D. Natali and M. Caironi, Adv. Mater, 24, 1357 (2012).

25. J. H. Schon and B. Batlogg, J. Appl. Phys, 89, 336 (2001).

26. J. Levinson, F. R. Shepherd, P. R. Scanlon, W. D. Westwood, G. Este, and M. Rider, J. Appl. Phys., 53, 1193 (1982). 